\title{
Use of moist oral snuff (snus) and pancreatic cancer: pooled analysis of nine prospective observational studies
}

Marzieh Araghi, ${ }^{1}$ (D) Maria Rosaria Galanti, ${ }^{1,2}$ Michael Lundberg, ${ }^{1}$ Anton Lager, ${ }^{1,2}$ Gunnar Engström, ${ }^{3}$ Lars Alfredsson, ${ }^{4}$ Anders Knutsson, ${ }^{5}$ Margareta Norberg, ${ }^{6}$ Malin Sund, ${ }^{7}$ Patrik Wennberg, ${ }^{8}$ Ylva Trolle Lagerros, ${ }^{9,10}$ Rino Bellocco, ${ }^{11,12}$ Nancy L. Pedersen, ${ }^{12}$ Per-Olof Östergren, ${ }^{13}$ Cecilia Magnusson ${ }^{1,2}$

${ }^{1}$ Department of Public Health Sciences, Karolinska Institutet, Stockholm, Sweden

${ }^{2}$ Centre for Epidemiology and Community Medicine, Stockholm Health Care District,

Stockholm County Council, Sweden

${ }^{3}$ Department of Clinical Sciences, Lund University, Lund, Sweden

${ }^{4}$ Institute of Environmental Medicine, Karolinska Institutet, Stockholm, Sweden

${ }^{5}$ Department of Health Sciences, Mid Sweden University, Sundsvall, Sweden

${ }^{6}$ Department of Public Health and Clinical Medicine, Epidemiology and Global Health, Umeå University, Umeå, Sweden

${ }^{7}$ Department of Surgical and Perioperative Sciences, Umeå University, Umeå, Sweden

${ }^{8}$ Division of Family Medicine, Department of Public Health and Clinical Medicine, Umeå University, Umeå, Sweden

${ }^{9}$ Department of Medicine, Clinical Epidemiology Unit, Karolinska Institutet, Stockholm, Sweden

${ }^{10}$ Department of Medicine, Clinic of Endocrinology, Metabolism and Diabetes, Karolinska University Hospital Huddinge, Stockholm, Sweden

${ }^{11}$ Department of Statistics and Quantitative Methods, University of Milano-Bicocca, Milan, Italy

${ }^{12}$ Department of Medical Epidemiology and Biostatistics, Karolinska Institutet, Stockholm, Sweden

${ }^{13}$ Social Medicine and Global Health, Department of Clinical Sciences, Lund University, Lund, Sweden

\section{Corresponding author:}

Dr. Marzieh Araghi. Department of Public Health Sciences, Karolinska Institutet Tomtebodavägen 18A, SE-171 77 Stockholm. (email: marzieh.araghi@ki.se).

\section{Novelty \& Impact Statements}

The study adds to the still ambiguous data regarding snus use and pancreatic cancer development. Swedish snus use does not appear to be implicated in the development of pancreatic cancer in men. Tobacco smoke constituents other than nicotine or its metabolites

may account for the relationship between smoking and pancreatic cancer.

This article has been accepted for publication and undergone full peer review but has not been through the copyediting, typesetting, pagination and proofreading process which may lead to differences between this version and the Version of Record. Please cite this article as an

'Accepted Article', doi: 10.1002/ijc.30773 


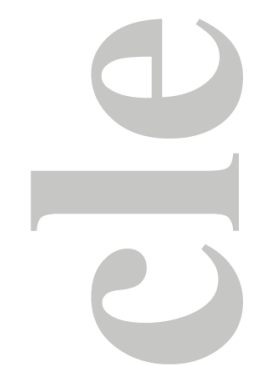

While smoking is a well-established risk factor for pancreatic cancer, the effect of smokeless tobacco is less well understood. We used pooled individual data from the Swedish Collaboration on Health Effects of Snus Use to assess the association between Swedish snus use and the risk of pancreatic cancer. A total of 424,152 male participants from nine cohort studies were followed up for risk of pancreatic cancer through linkage to health registers. We used shared frailty models with random effects at the study level, to estimate hazard ratios (HRs) and 95\% confidence intervals (CIs) adjusted for confounding factors. During 9,276,054 person-years of observation, 1,447 men developed pancreatic cancer. Compared to never snus use, current snus use was not associated with risk of pancreatic cancer (HR 0.96, 95\% CI 0.83 1.11) after adjustment for smoking. Swedish snus use does not appear to be implicated in the development of pancreatic cancer in men. Tobacco smoke constituents other than nicotine or its metabolites may account for the relationship between smoking and pancreatic cancer.

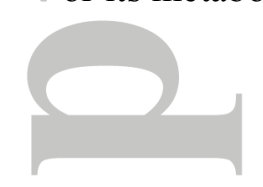

Key words: pancreatic cancer, incidence, snus

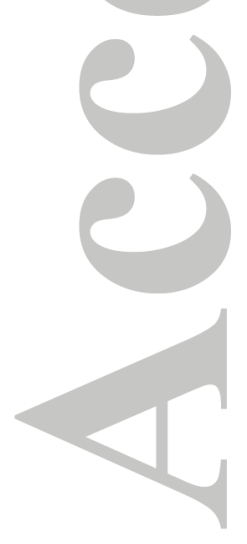

John Wiley \& Sons, Inc. 
Pancreatic cancer is one of the most lethal malignancies. ${ }^{1}$ In the year 2012, in Europe, there were 78,700 new cases and 77,900 deaths. ${ }^{2}$ Pancreatic cancer incidence rates are higher in the Nordic countries and Central Europe than in other parts of the world. ${ }^{3}$ Although the aetiology of pancreatic cancer remains poorly understood, cigarette smoking is a well-established and modifiable risk factor. ${ }^{1}$ A meta-analysis of 82 studies demonstrated that current and former smoking was associated with a $74 \%$ and a $20 \%$ increased risk of pancreatic cancer, respectively. ${ }^{4}$ The mechanism explaining the increased risk of pancreatic cancer with cigarette smoking is unclear, but a role of nicotine or its metabolites cannot be ruled out. ${ }^{5}$

Smokeless tobacco yields lower exposure to tobacco carcinogens compared with smoking, because it does not undergo combustion, but delivers an equivalent dose of nicotine. ${ }^{6}$ Smokeless tobacco products vary with respect to packaging, modality of use and known impact on cancer risks. ${ }^{7}$ Snus is a moist tobacco for oral use that is common in Scandinavian countries, where its use is increasing rapidly among young people. ${ }^{8}$ According to national public health surveys, about $18 \%$ of Swedish men and $27 \%$ of Norwegian young men are daily users. ${ }^{9}$ With the exception of Sweden, the sale of snus is currently banned in the European Union (EU). ${ }^{10}$ Swedish snus is known to deliver lower levels of carcinogenic tobacco-specific nitrosamines (TSNA) than North American smokeless tobacco products. ${ }^{7}$

Evidence regarding smokeless tobacco use and pancreatic risk is inconsistent. ${ }^{11-15}$ The International Agency for Research on Cancer (IARC) and European Community Scientific Committee on Emerging and Newly Identified Health Risks (SCENIHR) on the health effects of smokeless tobacco, in 2007 and 2008, respectively, concluded that smokeless tobacco products are carcinogenic to humans and the pancreas has been identified as a main target organ. ${ }^{11,12}$ A meta-analysis of 6 studies (including two Scandinavian studies of Swedish snus) by Boffetta and colleagues, ${ }^{13}$ also demonstrated a moderate risk increase, which emanated 
from the two included studies on snus use. ${ }^{13}$ Two recent meta-analyses ${ }^{14,}{ }^{15}$ of mainly European and North American case-control studies, however, did not find any association.

Assessing the effects of smokeless tobacco products may provide insights into carcinogenic mechanisms of smoking. Similar associations as for smoking would make a role of carcinogens not associated to combustion more likely. Hence, studies of snus are relevant not only to inform users and public health policy about the health consequences of snus, but also on the long-term safety of nicotine (often administered as nicotine replacement therapy or via e-cigarettes)

The Swedish Collaboration on Health Effects of Snus Use consists of a group of Swedish investigators, who have conducted prospective studies where data on snus use has been collected. ${ }^{16}$ The collaboration involves data from nine Swedish cohort studies, ${ }^{17-25}$ of which only one ${ }^{17}$ had published data on snus use and pancreatic cancer. We here take advantage of this large pooling project to investigate the impact of snus use on pancreatic cancer risk.

\section{Material and Methods}

\section{Contributing studies and data collection}

We used data from nine prospective cohort studies, including participants of varying ages, recruited at different time periods from diverse geographic regions across Sweden with information on both snus use and tobacco smoking. Exclusion criteria were pancreatic cancer prior to study enrolment, age less than 18 years or missing information on body mass index (BMI) (Figure 1). Since snus use is rare in women; ${ }^{9}$ the study was restricted to men. Details on study design and data collection procedures of the individual studies have been reported elsewhere. ${ }^{17-25}$ 
Each cohort study provided individual participant data, and data harmonization and analyses were implemented centrally. The specific studies were approved by their respective regional ethical vetting boards, and approval for the pooling project was granted by the Stockholm Regional Ethical Review Board (registration number 2009/971-31/3).

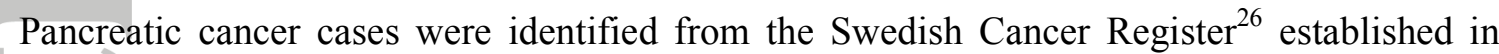
1958. ${ }^{26}$ Since the Swedish Cancer Register does not accept notifications from death certificates only, and therefore incompletely record pancreatic cancer because of their poor prognosis, ${ }^{27,28}$ we complemented our case ascertainment with data from the Cause of Death Register. The Cause of Death Register covers all deaths in Sweden since 1961, and includes ICD-codes for the main and contributory causes of death. ${ }^{29}$ Linkages were performed using the national registration number, an unique personal identifier assigned to all Swedish residents, ${ }^{29}$ and pancreatic cancer cases were identified by the ICD-7 code 157 and ICD-10 code $\mathrm{C} 25$

Information on tobacco use was collected at baseline using self-administered questionnaires in eight studies ${ }^{17-20,22-25}$ and by a structured telephone interview in one study. ${ }^{21}$ All studies contributed information on current snus use, and seven on former snus use $e^{17,19-21,23-25}$ while amount and duration of snus use was available from seven ${ }^{17-21,24,25}$ and five studies, ${ }^{17-19,24,25}$ respectively. Covariates collected at baseline, included body mass index (BMI), ${ }^{30}$ alcohol intake, ${ }^{31}$ physical activity level, ${ }^{32}$ and type 2 diabetes. ${ }^{33}$

Information on height and weight, whether it was self-reported ${ }^{20-23}$ or measured by health professionals, ${ }^{17-19,24,25}$ was collected in all studies. Information on alcohol consumption was retrieved from all studies, except one. ${ }^{17}$ Physical activity data was collected from seven studies, ${ }^{19-25}$ and diagnosis of type 2 diabetes were identified in five studies ${ }^{18,20,21,23,24}$ using several sources including self-reported data, record-linkage to the National Patient Register ${ }^{34}$ 
(ICD-9 code 250 and ICD-10 code E11 and E14) and Prescribed Drug Register (as antidiabetics, code A10 according the Anatomic Therapeutic Chemical classification system)..$^{35}$

Smoking and snus use was categorized into never, former and current users (where noncurrent snus use was treated as never use in the studies ${ }^{18,22}$ that did not have information on former snus use). Current snus use was further categorized according to amount consumed per week ( $<4$ cans, 4-6 cans, $\geq 7$ cans) and duration ( $<5$ years, $5-<10$ years, $10-<15$ years, $15-<20$ years, $\geq 20$ years) of use. Such information for smoking status was not available. Never-users of snus constituted the reference group.

Each cohort member contributed person-time from the date of entering into the study until the date of pancreatic cancer diagnosis, death, or the end of the study, whichever came first. Shared frailty models with random effects at the study level were used to estimate hazard ratios (HRs) with corresponding 95\% confidence intervals (CIs) of pancreatic cancer in relation to tobacco use, using attained age (in years) as the time scale. The shared frailty model is an extension of the Cox proportional hazards model and accounts for within study correlation by incorporating shared random effects. We tested for heterogeneity among included studies, using a $\mathrm{Q}$ test and $\mathrm{I}^{2}$ statistics. ${ }^{36}$ In addition to the inherent adjustment for age, all models were adjusted for body mass index $\left(\mathrm{BMI}, \mathrm{kg} / \mathrm{m}^{2}\right)$, calculated as body weight in (kilograms) by the height (in meters) squared and used as a continuous variable, and smoking (categorized as never, former or current smoking). Evaluation of the proportional hazards assumption with Schoenfeld's global test ${ }^{37}$ revealed that smoking status variable did not satisfy the proportional hazards assumption. Modelling was therefore performed using an extended Cox regression analysis, with inclusion of smoking as a time-varying covariate. 
All tests were 2 -sided, and we considered $p<0.05$ to be statistically significant. Stata statistical software (Version 13.0, Stata Corporation, and College Station, TX, USA) was used for all analyses.

We conducted sensitivity analysis according to the following scenarios: a) Using data from Cancer Register only. b) Excluding the Construction Workers Cohort, this dominates the results of our main analyses because of size. c) Adjusting for alcohol consumption (grams/week), physical activity ('less than 2 hours of light activity per week', 'more than 2 hours of light activity per week', ' 1 to 2 hours of at least moderate physical activity per week', and 'more than 2 hours of at least moderate physical activity per week'), and type 2 diabetes (yes/no) in the subset of studies where this information was available. ${ }^{18,20,21,23,24} \mathrm{~d}$ ) Excluding cohorts ${ }^{18,22}$ with no available information on former snus use, thus enabling correct classification of former snus use. e) Restriction to never smokers, as an alternative approach to control for the potential confounding effect of tobacco smoking.

\section{Results}

Figure 1 shows the numbers of study participants meeting the inclusion criteria. Characteristics of the 418,448 men constituting our analytical sample, yielding 9,276,054 person-years of observation, are shown in Table 1. Period of recruitment and duration of follow-up ranged from 1978 to 2013 and from 5 to 35 years, respectively. Average age at entry was 40 years (range 18 -99). A total of 1,423 incident cases of pancreatic cancer, including 424 solely identified from the Cause of Death Register, occurred during follow-up. At time of entry, $30 \%$ of study participants had ever used snus.

Our main analyses, including the full analytical sample and adjusting for smoking status, did not support any relationship between snus use and pancreatic cancer risk (HR 0.93, 95\% CI $0.82-1.06$, comparing ever to never snus users). Additionally, there was no indication that 
current snus use, regardless of its duration or intensity, affected the risk (Table 2). Study specific HRs of pancreatic cancer for current snus users as compared to never-snus users are shown in Figure 2. We observed a moderate degree of heterogeneity between studies $\left(\mathrm{I}^{2}\right.$ statistics 63\%).

\section{Sensitivity analysis}

Table 3 presents the results from sensitivity analyses. The estimates did change when using data from Cancer Register only. Excluding the Construction Workers Cohort, the HR for pancreatic cancer in current snus users was 1.30 (95\% CI $0.97-1.73)$ after adjustment for BMI and smoking status. In the subset of studies where further covariate information was available, additional adjustment for alcohol consumption, physical activity and interaction between alcohol consumption and smoking, yield the corresponding HR of 1.32 (95\% CI 0.84

- 2.08), and a similar result was produced with adjustment for diabetes (data not shown). Lastly, when the analytical sample was restricted to never smokers, the adjusted HR of pancreatic cancer in current snus users was 1.07 (95\% CI $0.77-1.50)$.

\section{Discussion}

Findings from this large pooling project, including nine prospective cohort studies and 1,423 incident cases, did not support any relationship between snus use and risk of pancreatic cancer in men regardless of timing, duration or intensity of use.

We judge prior evidence regarding the association between smokeless tobacco use and pancreatic cancer to be inconsistent. ${ }^{11-15}$ This is in spite of conclusions from prior and well recognized reviews, including the IARC Monograph $89,{ }^{11}$ a SCENIHR report, ${ }^{12}$ and a metaanalysis by Boffetta and colleagues. ${ }^{13}$ IARC Monograph $89^{11}$ based its review on four studies, including three from the US and one from Norway; a US cohort study ${ }^{38}$ reporting a relative risk (RR) of $1.70(95 \%$ CI $0.90-3.19)$ for ever users of smokeless tobacco after adjustment 
for smoking, a US case-control study ${ }^{39}$ showing an association with chewing tobacco but not snuff, another US case-control study, ${ }^{40}$ finding no overall association, but an apparent positive trend in risk with amount used. Lastly, a prospective cohort study of 10,136 Norwegian men recruited in 1966 and followed up to $2001,{ }^{41}$ reported no association with snus use in never smokers but an increased risk overall after adjustment for smoking (RR 1.67, 95\% CI 1.12 2.50). The SCENIHR report additionally considered data from the Swedish Construction Workers Cohort, ${ }^{17}$ which demonstrated an increased risk for snus use among never smokers (RR 2.00, 95\% CI 1.20 - 3.30) but not any overall association (RR 0.90, 95\% CI $0.70-1.20$, with adjustment for smoking). In contrast to the Norwegian study, Boffetta and colleagues ${ }^{13}$ meta-analysed the six studies cited above, resulting in a summary RR of $1.60(95 \%$ CI $1.10-$ 2.20) for any use of smokeless tobacco, but only based the analysis on the positive associations, i.e. the increased risk in never smokers from the Swedish Construction Workers Cohort $^{17}$ and overall increased risk in the Norway Cohorts Study, ${ }^{41,42}$ while ignoring the reciprocal null associations. Further reviews, a pooled analysis by Bertuccio and colleagues ${ }^{14}$ of eleven case-control and a meta-analysis by Lee and Hamling, ${ }^{15}$ did not support any association between smokeless tobacco use and pancreatic cancer.

Although snus use was not associated with risk in smoking-adjusted models in the Swedish Construction Workers Cohort, with follow-up until 2004, ${ }^{17}$ a twofold increased risk for ever or current snus users was observed when the sample was restricted to never smokers. We could replicate this result in our analyses, but the association was weaker and no longer statistically significant when the follow-up was extended until 2013 (HR 1.34, 95\% CI 0.90 1.99). Restricting to never smokers, we stratified our analyses of the Construction Workers Cohort according to calendar period of follow-up. The HR in current snus users was 1.98 $(0.97+4.03$, based on 4 exposed cases $)$ with follow-up from 1978 through 1994, but 1.11 (0.68 - 1.79, based on 27 exposed cases) in 1995-2013. The reason for this discrepancy is 
unclear, but may be due to increasing misclassification of exposure with longer follow-up (diluting any true associations), or to chance. The latter notion is sustained by our sensitivity analysis, excluding the Construction Workers Cohort, which was not in support of any strong relationship between snus and pancreatic cancer risk.

Our study has several strengths. Its prospective design minimises recall and selection bias, often afflicting retrospective studies. The latter bias is particularly problematic in studies of pancreatic cancer, since its high lethality imposes on case recruitment. Our study is also the largest to date, and we were hence able to explore dose-response relationships. In order to control for confounding by smoking, we used two approaches; multivariate modelling including current and former smoking as covariates, and restriction of the study population to never-smokers - both supporting a null association. In contrast to Boffetta and colleagues ${ }^{41}$ and Luo and colleagues, ${ }^{17}$ we had the opportunity to control for alcohol consumption, level of physical activity as well as diabetes, and again the main findings did not change. We used both Swedish Cancer Register and the Cause of Death Register to identify cancer cases, thus maximizing case ascertainment. ${ }^{26,43}$ Information on smoking and snus use was, however, selfreported, and only assessed at baseline. Although self-reports show high concordance with serum cotinine levels (a biomarker of smoking status) in cross-sectional data, ${ }^{44}$ tobacco habits may change over the life-course. Yet, Swedish data shows $70 \%$ of snus users at baseline continued use after ten years. ${ }^{45}$ Misclassification of tobacco use may nevertheless have biased our estimates of associations towards the null.

Tobacco smoking is a strong risk factor for pancreatic cancer. ${ }^{46}$ Tobacco smoke contains high doses of carcinogenic TSNAs, 4-(methylnitrosamino)-1-(3-pyridyl)-1-butanone (NNK) and $\mathrm{N}^{\prime}$-nitrosonornicotine $(\mathrm{NNN})$, which may have specificity for the pancreas. ${ }^{47} \mathrm{NNK}$ metabolites can bind to DNA to form adducts and induce activating point mutations in the RAS gene, ${ }^{48}$ which are thought to be the most common genetic alterations in the progression 
of pancreatic cancer. ${ }^{49}$ Nitrosamine levels are substantially lower in Swedish snus than in tobacco smoke, as well as than in other types of smokeless tobacco products, ${ }^{50}$ strengthening the plausibility of a null association between snus use and pancreatic cancer.

Our findings, from the largest sample to date, do not support a role of snus use in the development of pancreatic cancer in men. They, furthermore, point to tobacco smoke constituents other than nicotine or its metabolites, i.e. carcinogens associated with combustion, as the causal agent explaining the increased risk of pancreatic cancer in smokers.
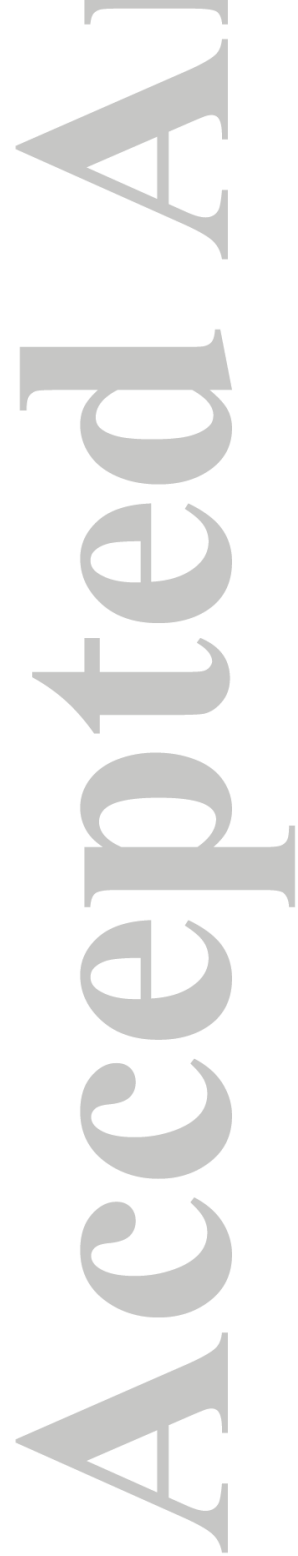


\section{References}

1. Yadav D, Lowenfels AB. The epidemiology of pancreatitis and pancreatic cancer. Gastroenterology 2013;144: 1252-61.

2. Ferlay J, Steliarova-Foucher E, Lortet-Tieulent J, Rosso S, Coebergh JW, Comber H, Forman D, Bray F. Cancer incidence and mortality patterns in Europe: estimates for 40 countries in 2012. Eur J Cancer 2013;49: 1374-403.

3. Bosetti C, Bertuccio P, Negri E, La Vecchia C, Zeegers MP, Boffetta P. Pancreatic cancer: overview of descriptive epidemiology. Mol Carcinog 2012;51: 3-13.

4. Iodice S, Gandini S, Maisonneuve P, Lowenfels AB. Tobacco and the risk of pancreatic cancer: a review and meta-analysis. Langenbeck's archives of surgery / Deutsche Gesellschaft fur Chirurgie 2008;393: 535-45.

5. Chowdhury P, MacLeod S, Udupa KB, Rayford PL. Pathophysiological effects of nicotine on the pancreas: an update. Exp Biol Med (Maywood) 2002;227: 445-54.

6. Holm H, Jarvis MJ, Russell MA, Feyerabend C. Nicotine intake and dependence in Swedish snuff takers. Psychopharmacology (Berl) 1992;108: 507-11.

7. Humans IWGotEoCRt. IARC Monographs on the Evaluation of Carcinogenic Risks to Humans, Smokeless Tobacco and Some Tobacco-specific N-Nitrosamines 2008;89.

8. Hamari AK, Toljamo TI, Kinnula VL, Nieminen PA. Dual use of cigarettes and Swedish snuff (snus) among young adults in Northern Finland. Eur J Public Health 2013;23: 768-71.

9. Public Health Agency of Sweden. Tobacco Habits. 2014.

10. Swedish Match.

11. Smokeless tobacco and some tobacco-specific N-nitrosamines. IARC Working Group on the Evaluation of Carcinogenic Risks to Humans. IARC Monogr Eval Carcinog Risks Hum. 2007; 89():1-592.

12. Scientific Committee on Emerging and Newly Identified Health Risks (SCENIHR) Health effects of smokeless tobacco products. Brussels: European Commission, Health \& Consumer Protection Directorate-General; 2008. http://ec.europa.eu/health/ph_risk/committees/04_scenihr/docs/scenihr_o_013.pdf

13. Boffetta P, Hecht S, Gray N, Gupta P, Straif K. Smokeless tobacco and cancer. Lancet Oncol 2008;9: 667-75.

14. Bertuccio P, La Vecchia C, Silverman DT, Petersen GM, Bracci PM, Negri E, Li D, Risch HA, Olson SH, Gallinger S, Miller AB, Bueno-de-Mesquita HB, et al. Cigar and pipe smoking, smokeless tobacco use and pancreatic cancer: an analysis from the International Pancreatic Cancer Case-Control Consortium (PanC4). Ann Oncol 2011;22: 1420-6.

15. Lee PN, Hamling J. Systematic review of the relation between smokeless tobacco and cancer in Europe and North America. Bmc Med 2009;7.

16. Hansson J, Galanti MR, Hergens MP, Fredlund P, Ahlbom A, Alfredsson L, Bellocco R, Eriksson M, Hallqvist J, Hedblad B, Jansson JH, Nilsson P, et al. Use of snus and acute myocardial infarction: pooled analysis of eight prospective observational studies. European journal of epidemiology 2012;27: 771-9.

17. Luo J, Ye W, Zendehdel K, Adami J, Adami HO, Boffetta P, Nyren O. Oral use of Swedish moist snuff (snus) and risk for cancer of the mouth, lung, and pancreas in male construction workers: a retrospective cohort study. Lancet 2007;369: 2015-20.

18. Manjer J, Carlsson S, Elmstahl S, Gullberg B, Janzon L, Lindstrom M, Mattisson I, Berglund G. The Malmo Diet and Cancer Study: representativity, cancer incidence and mortality in participants and non-participants. European journal of cancer 
prevention : the official journal of the European Cancer Prevention Organisation 2001;10: 489-99.

19. Eriksson M, Holmgren L, Janlert U, Jansson JH, Lundblad D, Stegmayr B, Soderberg S, Eliasson M. Large improvements in major cardiovascular risk factors in the population of northern Sweden: the MONICA study 1986-2009. Journal of internal medicine 2011;269: 219-31.

20. Trolle Lagerros Y, Hantikainen E, Mariosa D, Ye W, Adami HO, Grotta A, Ghilotti F, Bellocco R. The Swedish National March Cohort. International journal of epidemiology 2016.

21. Pedersen NL, Lichtenstein P, Svedberg P. The Swedish Twin Registry in the third millennium. Twin research : the official journal of the International Society for Twin Studies 2002;5: 427-32.

22. Carlsson F, Merlo J, Lindstrom M, Ostergren PO, Lithman $T$. Representativity of a postal public health questionnaire survey in Sweden, with special reference to ethnic differences in participation. Scandinavian journal of public health 2006;34: $132-9$.

23. Svensson AC, Fredlund P, Laflamme L, Hallqvist J, Alfredsson L, Ekbom A, Feychting M, Forsberg B, Pedersen NL, Vagero D, Magnusson C. Cohort profile: The Stockholm Public Health Cohort. International journal of epidemiology 2013;42: 1263-72.

24. Norberg M, Wall S, Boman K, Weinehall L. The Vasterbotten Intervention Programme: background, design and implications. Global health action 2010;3.

25. Alfredsson L, Hammar N, Fransson E, de Faire U, Hallqvist J, Knutsson A, Nilsson T, Theorell T, Westerholm P. Job strain and major risk factors for coronary heart disease among employed males and females in a Swedish study on work, lipids and fibrinogen. Scandinavian journal of work, environment \& health 2002;28: 238-48.

26. Mattsson B, Wallgren A. Completeness of the Swedish Cancer Register. Non-notified cancer cases recorded on death certificates in 1978. Acta Radiol Oncol 1984;23: 305-13.

27. Luo J, Adami HO, Reilly M, Ekbom A, Nordenvall C, Ye W. Interpreting trends of pancreatic cancer incidence and mortality: a nation-wide study in Sweden (19602003). Cancer causes \& control : CCC 2008;19: 89-96.

28. Hidalgo M, Cascinu S, Kleeff J, Labianca R, Lohr JM, Neoptolemos J, Real FX, Van Laethem JL, Heinemann V. Addressing the challenges of pancreatic cancer: future directions for improving outcomes. Pancreatology 2015;15: 8-18.

29. Johansson LA, Westerling R. Comparing Swedish hospital discharge records with death certificates: implications for mortality statistics. International journal of epidemiology 2000;29: 495-502.

30. Arslan AA, Helzlsouer KJ, Kooperberg C, Shu XO, Steplowski E, Buenode-Mesquita HB, Fuchs CS, Gross MD, Jacobs EJ, Lacroix AZ, Petersen GM, StolzenbergSolomon RZ, et al. Anthropometric measures, body mass index, and pancreatic cancer: a pooled analysis from the Pancreatic Cancer Cohort Consortium (PanScan). Arch Intern Med 2010;170: 791-802.

31. Genkinger JM, Spiegelman D, Anderson KE, Bergkvist L, Bernstein L, van den Brandt PA, English DR, Freudenheim JL, Fuchs CS, Giles GG, Giovannucci E, Hankinson SE, et al. Alcohol intake and pancreatic cancer risk: a pooled analysis of fourteen cohort studies. Cancer epidemiology, biomarkers \& prevention : a publication of the American Association for Cancer Research, cosponsored by the American Society of Preventive Oncology 2009;18: 765-76. 
32. Michaud DS, Giovannucci E, Willett WC, Colditz GA, Stampfer MJ, Fuchs CS. Physical activity, obesity, height, and the risk of pancreatic cancer. JAMA 2001;286: 9219.

33. Gullo L, Pezzilli R, Morselli-Labate AM, Italian Pancreatic Cancer Study G. Diabetes and the risk of pancreatic cancer. $N$ Engl J Med 1994;331: 81-4.

34. Ludvigsson JF, Andersson E, Ekbom A, Feychting M, Kim JL, Reuterwall C, Heurgren M, Olausson PO. External review and validation of the Swedish national inpatient register. BMC Public Health 2011;11: 450.

35. Wettermark B, Hammar N, Fored CM, Leimanis A, Otterblad Olausson P, Bergman U, Persson I, Sundstrom A, Westerholm B, Rosen M. The new Swedish Prescribed Drug Register--opportunities for pharmacoepidemiological research and experience from the first six months. Pharmacoepidemiol Drug Saf 2007;16: 726-35.

36. Higgins JPT, Thompson SG. Quantifying heterogeneity in a meta-analysis. Stat Med 2002;21: 1539-58.

37. Fine JP, Gray RJ. A proportional hazards model for the subdistribution of a competing risk. J Am Stat Assoc 1999;94: 496-509.

38. Zheng W, McLaughlin JK, Gridley G, Bjelke E, Schuman LM, Silverman DT, Wacholder S, Co-Chien HT, Blot WJ, Fraumeni JF, Jr. A cohort study of smoking, alcohol consumption, and dietary factors for pancreatic cancer (United States). Cancer causes \& control : CCC 1993;4: 477-82.

39. Muscat JE, Stellman SD, Hoffmann D, Wynder EL. Smoking and pancreatic cancer in men and women. Cancer epidemiology, biomarkers \& prevention : a publication of the American Association for Cancer Research, cosponsored by the American Society of Preventive Oncology 1997;6: 15-9.

40. Alguacil J, Silverman DT. Smokeless and other noncigarette tobacco use and pancreatic cancer: a case-control study based on direct interviews. Cancer epidemiology, biomarkers \& prevention : a publication of the American Association for Cancer Research, cosponsored by the American Society of Preventive Oncology 2004;13: 55-8.

41. Boffetta P, Aagnes B, Weiderpass E, Andersen A. Smokeless tobacco use and risk of cancer of the pancreas and other organs. International journal of cancer Journal international du cancer 2005;114: 992-5.

42. Lee PN, Hamling J. The relation between smokeless tobacco and cancer in Northern Europe and North America. A commentary on differences between the conclusions reached by two recent reviews. Bmc Cancer 2009;9.

43. Johansson LA, Bjorkenstam C, Westerling R. Unexplained differences between hospital and mortality data indicated mistakes in death certification: an investigation of 1,094 deaths in Sweden during 1995. Journal of clinical epidemiology 2009;62: 1202-9.

44. Eliasson M, Asplund K, Evrin PE, Lundblad D. Relationship of cigarette smoking and snuff dipping to plasma fibrinogen, fibrinolytic variables and serum insulin. The Northern Sweden MONICA Study. Atherosclerosis 1995;113: 41-53.

45. Norberg M, Lundqvist G, Nilsson M, Gilljam H, Weinehall L. Changing patterns of tobacco use in a middle-aged population - the role of snus, gender, age, and education. Global health action 2011;4.

46. Lynch SM, Vrieling A, Lubin JH, Kraft P, Mendelsohn JB, Hartge P, Canzian F, Steplowski E, Arslan AA, Gross M, Helzlsouer K, Jacobs EJ, et al. Cigarette smoking and pancreatic cancer: a pooled analysis from the pancreatic cancer cohort consortium. Am J Epidemiol 2009;170: 403-13.

47. Edderkaoui M, Thrower E. Smoking and Pancreatic Disease. J Cancer Ther 2013;4: 34-40. 
48. Schuller HM. Mechanisms of smoking-related lung and pancreatic adenocarcinoma development. Nat Rev Cancer 2002;2: 455-63.

49. Bardeesy N, DePinho RA. Pancreatic cancer biology and genetics. Nat Rev Cancer 2002;2: 897-909.

50. Foulds J, Ramstrom L, Burke M, Fagerstrom K. Effect of smokeless tobacco (snus) on smoking and public health in Sweden. Tob Control 2003;12: 349-59.
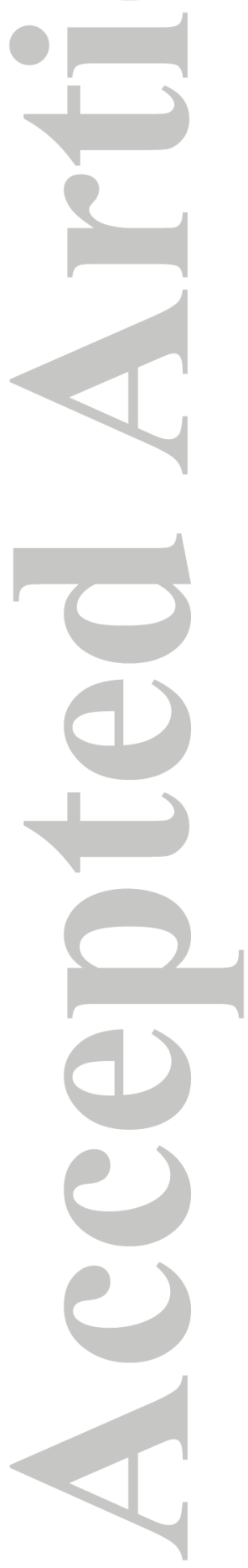
Table 1. Baseline characteristics of study participants in the Swedish Collaboration of Health Effects of Snus Use.

\begin{tabular}{|c|c|c|c|c|c|c|c|c|c|c|c|}
\hline \multirow{3}{*}{$\begin{array}{l}\text { Study } \\
\text { Construction Worker } \\
\text { Cohort }(\mathrm{CWC})^{17}\end{array}$} & \multirow{3}{*}{$\begin{array}{l}\text { Study population } \\
\begin{array}{l}\text { Construction workers, } \\
\text { national }\end{array}\end{array}$} & \multirow{3}{*}{$\begin{array}{c}\begin{array}{c}\text { Data } \\
\text { collection }\end{array} \\
\text { Questionnaire }\end{array}$} & \multirow{3}{*}{\begin{tabular}{|c|}
$\begin{array}{c}\text { Period } \\
\text { recruitment }\end{array}$ \\
$1978-1993$ \\
\end{tabular}} & \multirow{3}{*}{$\begin{array}{c}\text { Male } \\
\text { participants } \\
\text { (N) } \\
\\
273,604\end{array}$} & \multirow{3}{*}{\begin{tabular}{|c|}
$\begin{array}{c}\text { Person } \\
\text { years of } \\
\text { follow-up } \\
\text { (N) }\end{array}$ \\
$7,699,364$ \\
\end{tabular}} & \multirow{3}{*}{$\begin{array}{c}\begin{array}{c}\text { Mean age at } \\
\text { recruitment } \\
\text { (years) }\end{array} \\
34\end{array}$} & \multirow{3}{*}{$\begin{array}{c}\begin{array}{c}\text { Cases } \\
(\mathbf{N})\end{array} \\
1,025 \\
\end{array}$} & \multirow{3}{*}{$\begin{array}{c}\begin{array}{c}\text { Current } \\
\text { snus } \\
\text { users } \\
(\%)\end{array} \\
26 \\
\end{array}$} & \multicolumn{3}{|c|}{$\begin{array}{l}\text { Information available } \\
\text { regarding snus use }\end{array}$} \\
\hline & & & & & & & & & Duration & Amount & $\begin{array}{l}\text { Former } \\
\text { use }\end{array}$ \\
\hline & & & & & & & & & Yes & Yes & Yes \\
\hline $\begin{array}{l}\text { Malmö diet and Cancer } \\
\text { Study (MDCS) }\end{array}$ & $\begin{array}{l}\text { Population-based, Malmö } \\
\text { City }\end{array}$ & Questionnaire & 1991-1996 & 11,217 & 207,444 & 59 & 63 & 7 & No & Yes & No \\
\hline $\begin{array}{l}\text { Multinational } \\
\text { Monitoring of Trends } \\
\text { and Determinants in } \\
\text { Cardiovascular Disease } \\
\text { (MONICA) }{ }^{19}\end{array}$ & $\begin{array}{l}\text { Population-based, } \\
\text { Norrbotten and } \\
\text { Västerbotten Counties }\end{array}$ & Questionnaire & $1986-2004$ & 4,474 & 57,109 & 48 & 14 & 23 & Yes & Yes & Yes \\
\hline $\begin{array}{l}\text { National March Cohort } \\
(\mathrm{NMC})^{20}\end{array}$ & $\begin{array}{l}\text { Participants in a charity } \\
\text { walk, national }\end{array}$ & Questionnaire & 1997 & 13,305 & 181,464 & 52 & 54 & 10 & Yes & Yes & Yes \\
\hline $\begin{array}{l}\text { Screening Across the } \\
\text { Lifespan Twin Study } \\
(\text { SALT) })^{21}\end{array}$ & $\begin{array}{l}\text { Twins born in Sweden } \\
\text { between 1926-1958, } \\
\text { national }\end{array}$ & $\begin{array}{l}\text { Structured } \\
\text { telephone } \\
\text { interview }\end{array}$ & 1998-2002 & 17,923 & 174,124 & 56 & 85 & 15 & Yes & Yes & Yes \\
\hline $\begin{array}{l}\text { Scania Public Health } \\
\text { Cohort (Scania_PHC) }{ }^{22}\end{array}$ & $\begin{array}{l}\text { Population-based, Scania } \\
\text { County }\end{array}$ & Questionnaire & 1999 & 5,837 & 54,647 & 48 & 3 & 20 & No & No & No \\
\hline $\begin{array}{l}\text { Stockholm Public } \\
\text { Health Cohort } \\
(\text { Sthlm_PHC) }\end{array}$ & $\begin{array}{l}\text { Population-based, } \\
\text { Stockholm County }\end{array}$ & Questionnaire & $2002-2010$ & 37,807 & 185,581 & 49 & 42 & 18 & No & No & Yes \\
\hline $\begin{array}{l}\text { Västerbotten } \\
\text { Intervention Programme } \\
(\text { VIP })^{24}\end{array}$ & $\begin{array}{l}\text { Population-based, } \\
\text { Västerbotten County }\end{array}$ & Questionnaire & $1992-2013$ & 47,181 & 616,045 & 47 & 129 & 27 & Yes & Yes & Yes \\
\hline $\begin{array}{l}\text { Work, Lipids and } \\
\text { Fibrinogen Study } \\
\text { (WOLF) }^{25}\end{array}$ & $\begin{array}{l}\text { Employees, Västernorrland, } \\
\text { Jämtland, and Stockholm } \\
\text { Counties }\end{array}$ & Questionnaire & $1992-1997$ & 7,100 & 100,276 & 42 & 8 & 23 & Yes & Yes & Yes \\
\hline All studies & & & $1978-2013$ & 418,448 & $9,276,054$ & 40 & 1,423 & 24 & & & \\
\hline
\end{tabular}




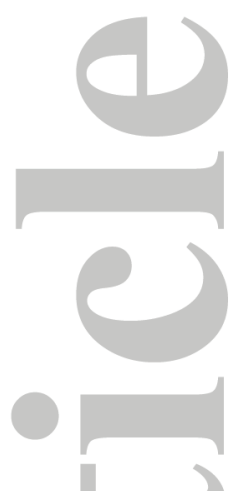

Table 2. Pooled hazard ratios and $95 \%$ confidence intervals for pancreatic cancer in relation to snus use.

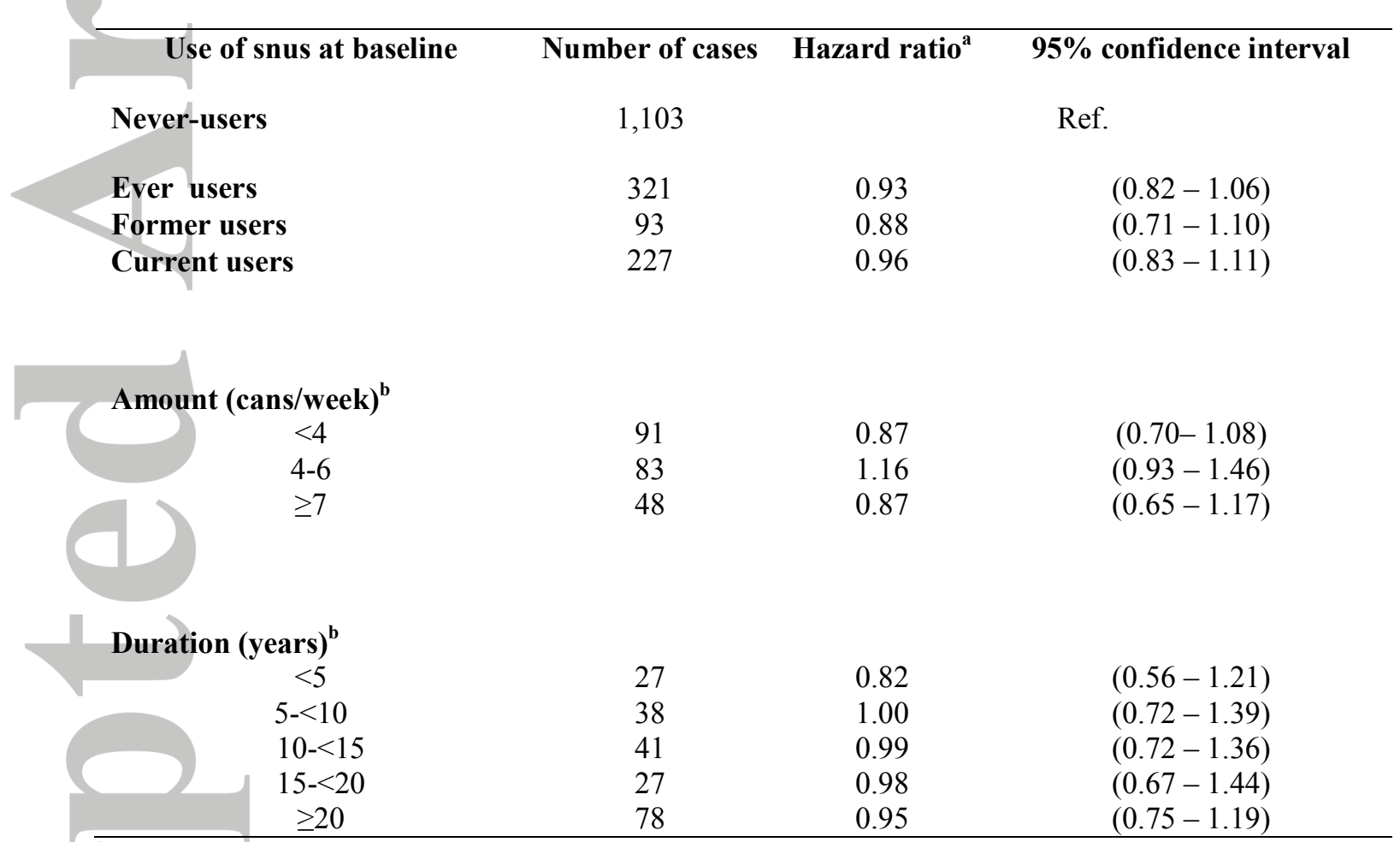

${ }^{a}$ All hazard ratio estimates were adjusted for attained age, smoking (never, former, and current) and body mass index. ${ }^{\mathrm{b}}$ Among current snus users only.

2

John Wiley \& Sons, Inc.

This article is protected by copyright. All rights reserved. 


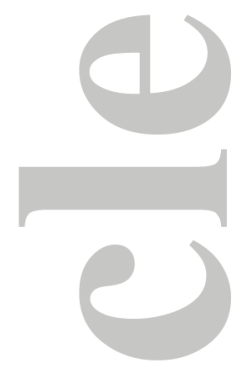

Table 3. Pooled hazard ratios (HR) and $95 \%$ confidence intervals (CI) of pancreatic cancer in relation to snus use from sensitivity analyses.

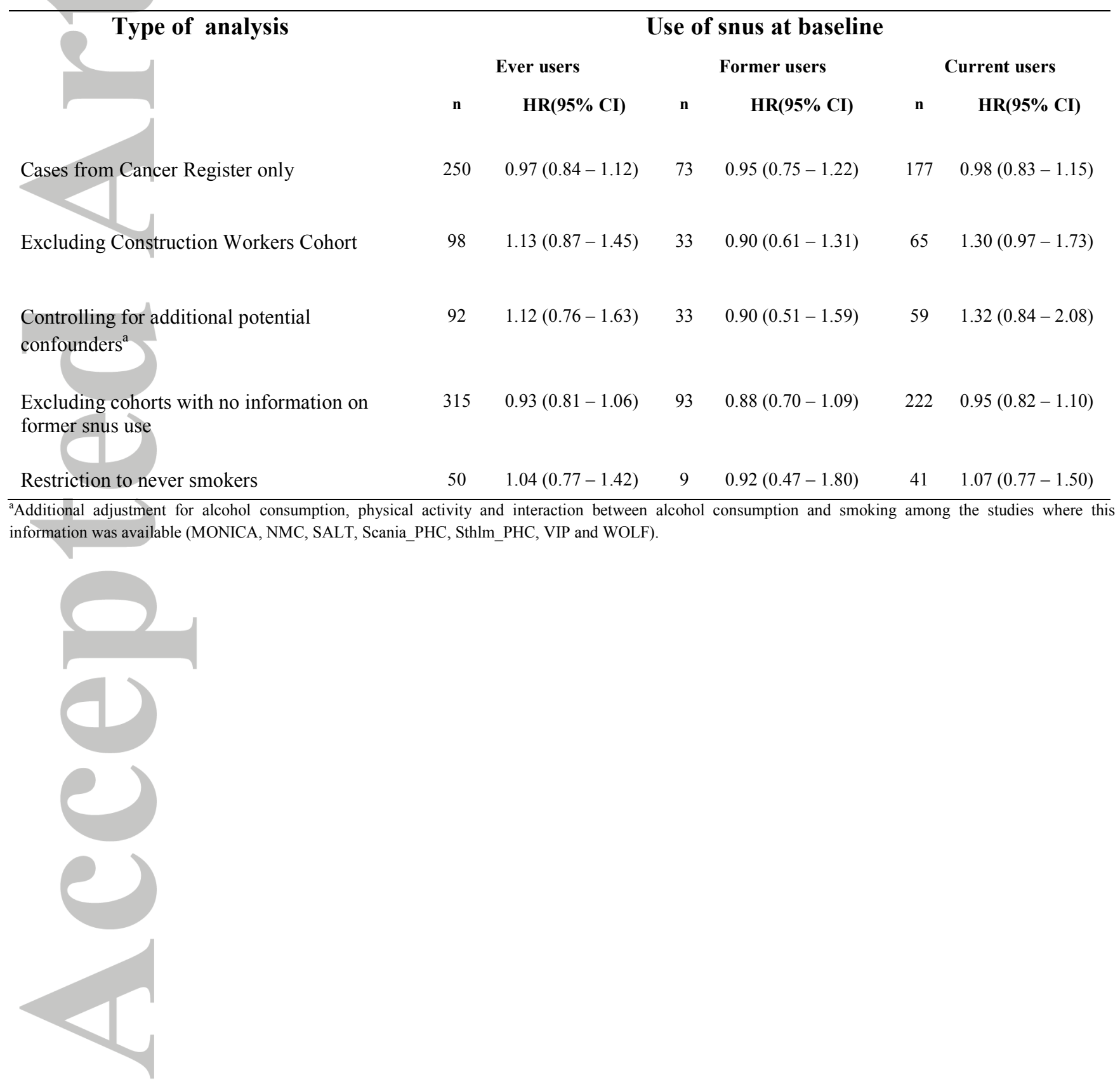

3

John Wiley \& Sons, Inc.

This article is protected by copyright. All rights reserved. 
The Swedish Collaboration on Health Effects of Snus Use 432,994 participants from nine cohort studies

Age $<18$ years

6,697 participants excluded

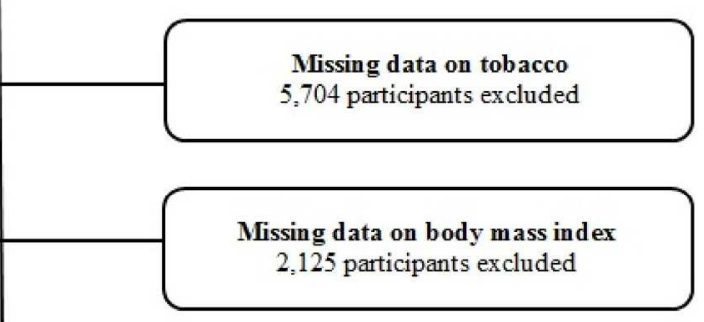

Pancreatic cancer diagnosis before entry 8 participants excluded

Death before study start date 12 participants cxcluded

Final analytical sample

418,448 participants (14,546 excluded)

Figure 1. Derivation of the analytical sample.

$189 \times 176 \mathrm{~mm}(300 \times 300 \mathrm{DPI})$

John Wiley \& Sons, Inc.

This article is protected by copyright. All rights reserved. 


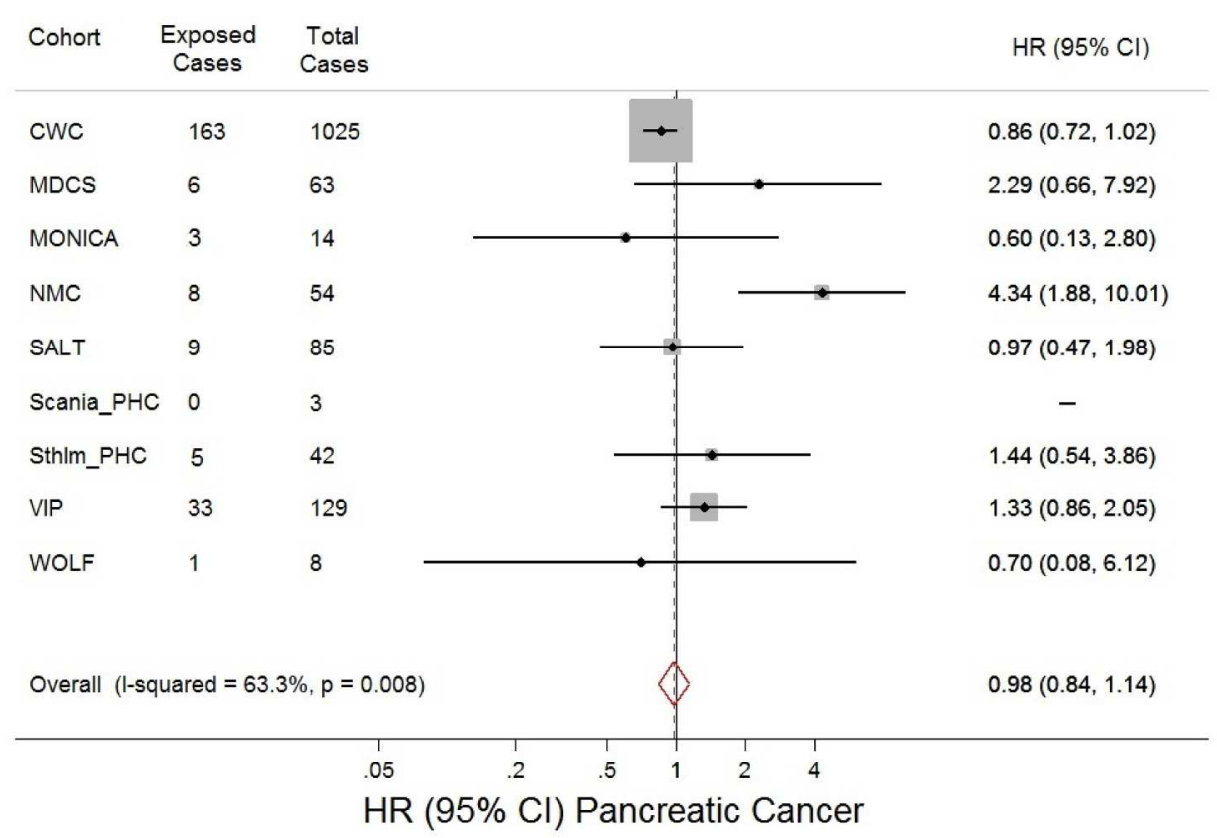

Figure 2. Study-specific hazard ratios (HR) and 95 percent confidence intervals (95\% CI) of pancreatic cancer among current-snus users versus never-snus users."

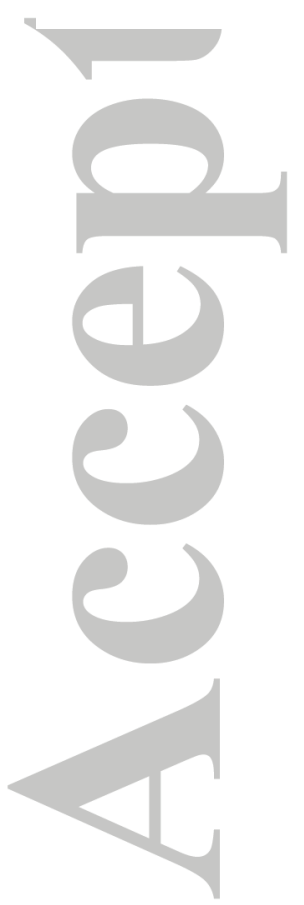

$201 \times 149 \mathrm{~mm}(300 \times 300$ DPI $)$

John Wiley \& Sons, Inc.

This article is protected by copyright. All rights reserved. 